\title{
How Challenge Stress Affects Mental Health among College Students during the COVID-19 Pandemic: The Moderating Role of Self-Efficacy
}

\author{
Yan Zeng ${ }^{1, \#}$, Shaoping Qiu ${ }^{2, \#, *}$, Amin Alizadeh $^{3}$ and Tiefang Liu ${ }^{4}$ \\ ${ }^{1}$ The School of Literature and Communication, Guangdong Polytechnic Normal University, Guangzhou, 510665, China \\ ${ }^{2}$ The Department of Engineering Technology \& Industrial Distribution, Texas A\&M University, College Station, 77843, USA \\ ${ }^{3}$ The Department of Educational Administration \& Human Resource Development, Texas A\&M University, College Station, \\ 77843, USA \\ ${ }^{4}$ The School of Educational Science, Hunan Normal University, Changsha, 410081, China \\ *Corresponding Author: Shaoping Qiu. Email: qap5415@gmail.com \\ \#The first two authors (Yan Zeng and Shaoping Qiu) contributed equally to this paper and should be considered co-first authors \\ Received: 25 January 2021 Accepted: 05 March 2021
}

\begin{abstract}
While a plethora of studies has been conducted to examine stress and its impact on mental health in western countries, research is scarce investigating the relationship between student challenge stress and health illness in the context of Chinese colleges. No studies examined the moderating effect of self-efficacy on the relationship between challenge stress and health illness. This study attempted to investigate the relationships between these three variables among Chinese college students. Especially, this study focused on examining whether self-efficacy moderated the effect of perceived challenge stress on students' mental health. Also, the differences were tested between male and female students in terms of these three variables. A sample of 578 Chinese college students was recruited over an approximately 12 -week period from 7 Chinese universities. An online survey link was distributed through WeChat. The SPSS version 26 software was used to analyze the data. Results showed that there is no significant difference between genders in terms of perceived challenge stress, self-efficacy, and students' mental health. In addition, challenge stress was positively related to the students' mental health $(\beta=0.35, p<0.01)$ while there was a negative association between self-efficacy and mental health $(\beta=-0.41, p<0.01)$. Furthermore, selfefficacy plays a moderating role in the relationship between challenge stress and mental health $(\beta=-0.11$, $p=0.02$ ). Students with low self-efficacy tend to experience more mental health issues. It is suggested that Chinese colleges and universities pay more attention to students with low self-efficacy, either through faculty/staff interventions or peer counseling. Professors consider reducing students' academic stress to improve their mental health.
\end{abstract}

\section{KEYWORDS}

Challenge stress; self-efficacy; mental health; college students

\section{Introduction}

Life in college is one of the most stressful periods [1]. College students experience a unique developmental stage of psychosocial development as they transition from late adolescence to adulthood [2]. Concomitant with this transition, stress results and accrues. As a psychological construct, stress has 
been defined as a feeling of physical and emotional anxiety or tension that directly influences behavior [3]. Research has shown that college student stress mostly comes from financial problems, classwork, academic performance, move away from home, and changes in social relationships [4]. Like their counterparts in other countries, Chinese college students also experience stress, to a lesser extent though. A study has demonstrated that, while only $0.3 \%$ and $8.4 \%$ of Chinese college students reported they were shouldering severe and high levels of stress, respectively, $49.3 \%$ of them declared they experience minor stress [5]. This number is alarming given that there are millions of students studying in various types of colleges and universities in China. However, what Chinese college students concern about most is their academic stress, interpersonal relationships, and future career and/or finding a job after graduation [6]. A survey conducted in 2020 reported that $60 \%$ of Chinese college students have been obsessed with academic stress in recent years [7]. Especially during the time of the COVID-19 outbreak, city lockdown, strict quarantine, and movement restriction had been practiced in China. College students had to stay home to take the online courses, which added more psychological stress and led to anxiety, depression, anger, and emotional exhaustion [8].

Just as stress is very common among college students, so is mental illness [1,9]. It appears that college students experiencing higher levels of stress also exhibit more susceptibility to mental health problems [9]. Scientific evidence has shown college student stress culminates in various health issues [10]. For example, college students with high levels of stress are more likely to develop depressive symptoms and suicide ideation [11]. Liu et al. [12] declared that one out of five college students in China deals with at least one form of mental health issues.

While college student stress raises the risk of mental disorder, self-efficacy may buffer the effect of stress on health problems. Self-efficacy is defined as one's belief that he or she can finish any given task successfully. Especially, self-efficacy for college students refers to confidence in completing schoolwork such as preparing for tests and asking questions in class [13]. According to the Conservation of Resources (COR) Theory [14], students' self-efficacy is one type of psychological capital. To some extent, this psychological capital may present a crucial personal resource that offsets the effect of stress and relieves students' anxiety [15], thus reducing the intensity of health problems. It has been found that when facing a high level of stress, individuals with higher self-efficacy tend to manage the stress more successfully [16]. However, the empirical results are not quite consistent. For example, Chan's [17] study suggested that self-efficacy does not have any impact on stress and mental health among Chinese schoolteachers. Furthermore, the buffering effect of self-efficacy on the relationship between stress and mental health has, to the best of our knowledge, rarely been examined among college students in general and the Chinese college students in particular.

This study used Chinese college students as participants. Instead of focusing on generic stress, we focused on students' challenge stress because it is most prevalent among college students. Challenge stress is anxiety or tension that causes pressure but at the same time induces work motivation [18]. While a plethora of studies has been conducted to examine stress and its impact on mental health in western countries [19,20], research is scarce investigating the relationship between student challenge stress and health illness in the context of Chinese colleges. The relationship between challenge stress and mental health among Chinese college students remains unclear. The main purposes of this study were threefold. First, we attempted to investigate whether there are any differences between genders in their perception of challenge stress and self-efficacy. Second, we attempted to analyze the relationships between challenge stress, self-efficacy, and mental illness among Chinese college students. Third, we were especially interested in examining whether self-efficacy moderates the effect of perceived challenge stress on mental health. 


\section{Materials \& Methods}

\subsection{Participants and Study Design}

This study adopted a cross-sectional research design. The data were collected between April and July 2020 at 7 universities in China during the outbreak of the COVID-19 pandemic. We elicited research participants from undergraduate students employing convenience and snowball sampling strategy. This study was approved by the Ethics Committee of a University in the southern part of China. Prior to the survey, approvals were also obtained from respective universities to distribute the survey to students. WeChat, a popular Chinese social media, was used to send an online survey link to college students. An informed consent form was embedded in the survey before the questionnaires. Students were allowed sufficient time to read and decide whether to participate. If they agreed to take part in the study, they can proceed to complete the survey. Otherwise, they can stop and exit. After completing the survey, participants were asked to distribute the survey link to as many classmates as possible. Previous research showed that online social media and traditional paper surveys exhibit measurement invariance and there is no evidence of differential effects across modes of data collection [21]. Because the survey instruments we used were initially developed and used in the Western countries, we performed a back-translation to ensure that the meaning of instrument items was accurate and culturally appropriate. A total of 747 college students participated in the study and returned their survey. However, 169 students provided incomplete data. Therefore, we obtained 578 valid and usable data cases.

Among these 578 college student participants, 145 (25.1\%) were men while 433 (74.9\%) were women. They were from all parts of China, except for Xinjiang, Tibet, Qinghai, Hong Kong, and Macao. Their average age was 20.93 years old $(\mathrm{SD}=1.20)$. A total of $243(42.0 \%)$ college students were freshmen, whereas $240(41.4 \%)$ participants were sophomores. Only $95(16.5 \%)$ were junior and senior students. The average annual family income was $38114.52 \mathrm{RMB}$ yuan.

\subsection{Measures}

All instruments were well-developed and validated in western countries. Altogether, there were 21 instrument items in the survey to assess students' challenge stress, self-efficacy, and mental health. The demographic questions included age, gender, student's major, grade, and family income. Participants' confidentiality was guaranteed. To minimize common method bias, we used a couple of negatively worded items in the survey [22].

Challenge stress was assessed using LePine et al. [18] 5-item measure. Two sample items were: "The volume of coursework that must be completed in my classes" and "The amount of time spent working on projects/assignments for my classes". Students were asked to respond to the extent to which they experienced challenge stress by using a 5 -point scale $(1=$ no stress to $5=$ a great deal of stress). Cronbach's Alpha was acceptable at 0.89 .

Self-efficacy was measured using the 10-item scale developed by Schwarzer et al. [23]. Students responded to all these items using a 5-point scale ranging from 1 (strongly disagree) to 5 (strongly agree). One example item was "It is easy for me to stick to my aims and accomplish my goals." The reliability of this scale $\alpha=0.90$.

Mental health was evaluated by K6 six-item scale developed by Kessler et al. [24] Students are required to rate on a scale of 1 (never) to 5 (very often) how often they felt nervous, hopeless, restless or fidgety, depressed, everything was an effort, and worthless. This scale had an adequate internal consistency of 0.90 .

Control variable. In this study, we controlled for age, gender, and grade. These variables were found to be associated with challenge stress and mental illness in previous studies [25,26]. We coded male as " 1 " and female as "2" for gender. For grade, we coded freshman as "1", sophomore "2", junior "3", and senior "4". Age was a continuous variable. 


\subsection{Statistical Analysis}

We used SPSS version 26 to perform statistical analysis. Independent sample $t$-tests were conducted to examine whether there were gender differences in terms of three variables of interest: perceived challenge stress, self-efficacy, and mental illness. We also adopted Hayes's PROCESS to examine whether there are relationships between these three variables and the moderating effect of self-efficacy after controlling for students' age, gender, grade, and major.

\section{Results}

Harman's single factor test was conducted to check the common method variance in the data. Results showed that only 35.13 percent of the variance was accounted for by one single factor, indicating common method variance was not a major issue. The descriptive statistics (mean and standard deviation), reliability, and bivariate correlations between variables were presented in Tab. 1.

Table 1: Means (M), standard deviations (SD), reliabilities, and bivariate correlations between variables

\begin{tabular}{llllllll}
\hline & $\mathrm{M}$ & $\mathrm{SD}$ & 1 & 2 & 3 & 4 & 5 \\
\hline 1. CS & 3.24 & 0.82 & 0.89 & & & & \\
2. SE & 3.21 & 0.66 & $-0.25^{* *}$ & 0.90 & & & \\
3. MI & 2.46 & 0.87 & $0.40^{* *}$ & $-0.39^{* *}$ & 0.90 & & \\
Control variables & & & & & & & \\
4. Gender & 1.75 & 0.43 & 0.06 & -0.06 & -0.05 & & \\
5. Age & 20.93 & 1.20 & $-0.14^{* *}$ & 0.00 & -0.03 & -0.10 & \\
6. Grade & 1.81 & 0.86 & $-0.12^{* *}$ & 0.07 & -0.02 & -0.00 & $0.70^{* *}$ \\
\hline
\end{tabular}

Note: $\mathrm{N}=578 . \mathrm{CS}$ represents challenge stress; SE is self-efficacy; MI denotes mental health. ${ }^{*}$ Correlation is significant at 0.05 level (2-tailed). ** Correlation is significant at 0.01 level (2-tailed). On the diagonal are Cronbach's Alphas.

As indicated in Tab. 1, age $(\mathrm{r}=-0.14, p<0.01)$ and grade $(\mathrm{r}=-0.12, p<0.01)$ are negatively related to challenge stress $(\mathrm{r}=0.15, p<0.01)$. That is to say older and higher-grade students have a lower level of perceived challenge stress. There are no associations between other control variables and three study variables in this study. Mental health is positively and significantly correlated to challenge stress $(\mathrm{r}=0.40, p<0.01)$, whereas challenge stress is negatively and significantly related to self-efficacy $(\mathrm{r}=$ $-0.25, p<0.01)$. The relationship between mental health and self-efficacy is negative and significant $(\mathrm{r}=$ $-0.39, p<0.01)$. Results from independent sample t-tests showed that no statistically significant differences exist between men and women in perceived challenge stress $(\mathrm{t}=-1.48, p=0.14)$ and selfefficacy $(\mathrm{t}=1.55, p=0,12)$.

We further used Hayes's PROCESS v 3.5 to examine the relationships between perceived challenge stress, self-efficacy, and mental health, as well as testing whether self-efficacy moderates the effect of challenge stress on mental health. We mean-centered the scores of challenge stress and self-efficacy in order to mitigate the problem of multicollinearity [27]. The results of the analyses are presented in Tab. 2. A total of $51.56 \%$ of the variance is accounted for by the model.

Evaluation of the path coefficients indicated that challenge stress was positively associated with mental health $(\beta=0.35, p<0.01)$. The more challenge stress college students have to shoulder, the more likely they would suffer from mental health. In contrast, college students feel more psychologically healthy if they study under low-level challenge stress. In addition, self-efficacy negatively predicts students' mental health ( $\beta=-0.41, p<0.01$ ), indicating that college students with a high level of self-efficacy less likely experience mental health problems. Furthermore, gender was negatively linked to mental health. Most 
importantly, the results indicated that the interaction term between challenge stress and self-efficacy significantly predicted mental health at 0.05 significant level $(\beta=-0.11, p=0.02)$. Hence, self-efficacy plays a moderating role between challenge stress and mental health among college students.

Table 2: Results of the regression analyses (Outcome variable: MI)

\begin{tabular}{lllllll}
\hline Variable & coeff & $\mathrm{se}$ & $\mathrm{t}$ & $\mathrm{p}$ & LLCI & ULCI \\
\hline CS & $0.35^{* *}$ & 0.04 & 8.68 & 0.00 & 0.27 & 0.43 \\
$\mathrm{SE}$ & $-0.41^{* *}$ & 0.05 & -8.29 & 0.00 & -0.51 & -0.31 \\
Int & $-0.11^{*}$ & 0.04 & -2.43 & 0.02 & -0.19 & -0.02 \\
Major & -0.00 & 0.07 & -0.05 & 0.96 & -0.15 & 0.14 \\
Gender & $-0.18^{*}$ & 0.08 & -2.36 & 0.02 & -0.34 & -0.03 \\
Age & -0.02 & 0.04 & -0.66 & 0.51 & -0.10 & 0.05 \\
Grade & 0.09 & 0.05 & 1.32 & 0.19 & -0.03 & 0.17 \\
\hline
\end{tabular}

Note: Coeff = regression coefficient; $\mathrm{se}=$ standard error; CS represents challenge stress; SE is self-efficacy; MI denotes mental health; Int is interaction term. All values were standardized regression coefficients. ${ }^{*}$ Coefficient is significant at 0.05 level (2-tailed). ${ }^{* *}$ Coefficient is significant at 0.01 level (2-tailed)

We adopted the pick-a-point approach and plotted the regression of mental illness on challenge stress to evaluate the moderating effect at two scores of self-efficacy (mean +1 standard deviation and mean - 1 standard deviation). These two points represented high level and low level of self-efficacy among college students $(\beta=-0.18, p=0.02)$. Fig. 1 reflects the estimated goodness of fit regression lines for both high level vs. low level of self-efficacy. The regression analysis results indicated that for both high and low levels of self-efficacy, mental health is positively associated with challenge stress. However, the regression coefficients are different. For students with low self-efficacy, challenge stress appears to be related to more mental health. In contrast, students with high self-efficacy experience fewer mental health problems if the same level of challenge stress is imposed on them.

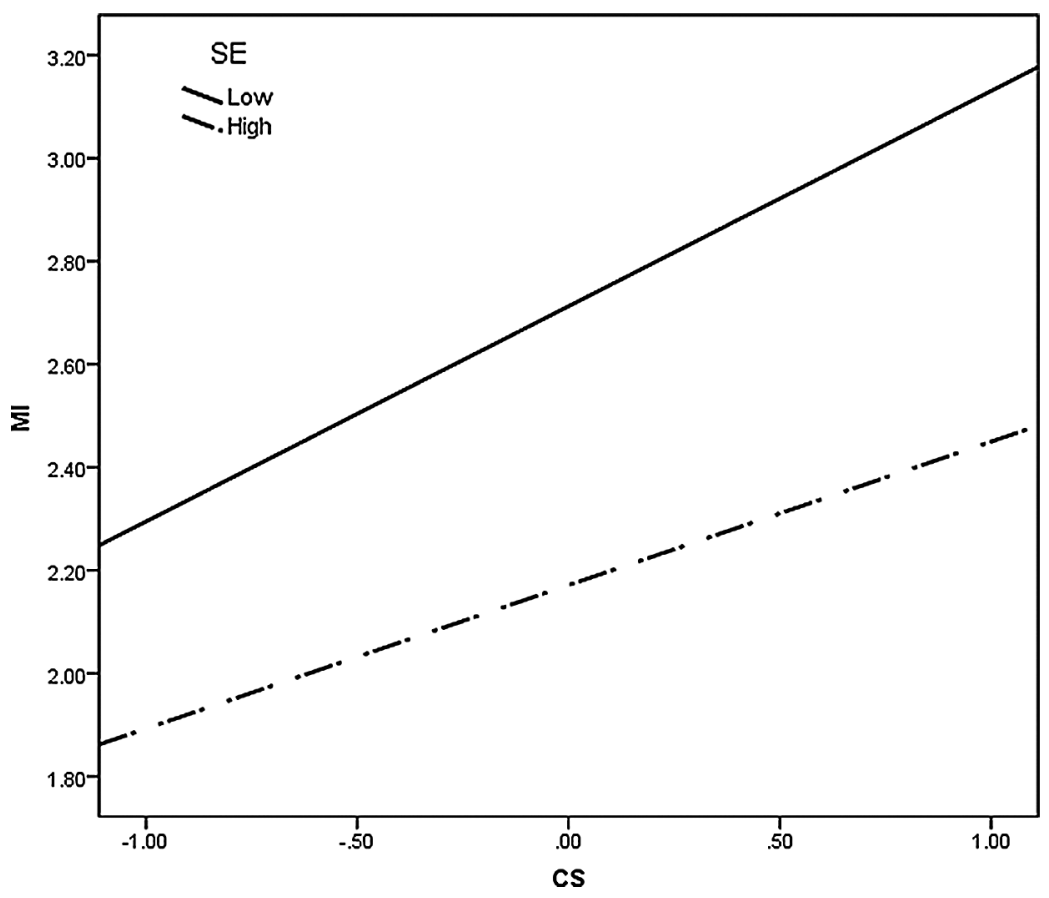

Figure 1: Moderation effect between challenge stress and self-efficacy on mental health Note: CS represents challenge stress; SE is self-efficacy; MI denotes mental health 
It would be also interesting to check whether self-efficacy is a statistically significant moderator across male and female students. For the female student group, the interaction term between challenge stress and self-efficacy still significantly predicted mental health at 0.05 significant level $(\beta=-0.10, p=0.04)$. However, for male students, self-efficacy was not a statistically strong moderator any more at 0.05 significant level $(\beta=-0.13, p=0.14)$, even though the regression coefficient was larger than both female students and the whole group. The reason might be the small sample size of only 145 male participants, which reduced the power to detect the moderation effect in the male student group.

\section{Discussion}

The purposes of this study were to (1) test whether there are any differences between genders in challenge stress and self-efficacy (2) examine the relationships among perceived challenge stress, selfefficacy, and reported mental health among Chinese college students. Particularly, this study examined whether perceived challenge stress and self-efficacy were directly associated with students' mental health and whether self-efficacy moderated the relationship between perceived challenge stress and students' mental health. As anticipated, challenge stress was positively related to the students' mental illness while there was a negative association between self-efficacy and mental health. In addition, self-efficacy was found to interact with challenge stress to affect the students' mental health.

No significant differences were found between genders in terms of challenge stress and self-efficacy. There are several possible reasons. First, we conducted this study during the outbreak season of COVID-19 when students were instructed online from home. Since this never happened before, the course syllabus and teachers' requirements have been changed to adapt to the new study environment. The students might perceive less academic stress than the influence of coronavirus demand. Therefore, stress levels do not vary much across different genders. Second, with the advancement of technology, many apps are developed readily available for educational purposes that assist college students to learn in less time. Effective use of the internet helps the students to obtain instant information and thus saves much time versus referring to books [28]. Third, family support and college online counseling provided to students might greatly relieve students' stress during the COVID-19 pandemic.

It can be seen from the results of regression analyses that gender is a strong predictor of students' mental health. Male students tend to experience more mental health issues than female counterparts. This finding is not consistent with the study conducted in India by Pant et al. [29] that showed no significant difference between male and female students in terms of mental health. However, it is worth noting that the correlation between gender and mental health was not significant in the current study. The correlationregression incongruence can be explained by two possible reasons. First, the correlation between gender and health in this research is simply a zero-order correlation without controlling for the influence of any other variables. In contrast, regression coefficient tests the association between independent variable and outcome variable, accounting for the effect of other predictors [30]. When other predictors enter the equation, the magnitude, significance, even the sign might change. Second, there might be other suppressor variables in the study, enhancing the magnitude of regression coefficient associated with gender or gender itself was such a variable [31]. Detecting which one (s) is (are) suppressor variable(s) falls behind the scope of this study.

This study contributes to stress and health research. First, we found that there is no gender difference in challenge stress among Chinese college students during the hard time. The results from previous research were mixed in this regard. While some research suggested that female college students report a higher level of stress than their counterparts [32,33], other studies did not find any strong evidence to suggest that men or women students experience any greater (or less) stress [34,35]. This study supports the conclusion of the latter research stream by particularly focusing on Chinese college students. Mixed results in the literature reflect the fact, like other variables, that perceived stress is a complex 
psychological phenomenon that might be influenced by multiple contextual factors in addition to gender. It might also depend on the situation and cultural context. Apparently, more research is needed to further explore this topic, especially in other cultures and different situations. Second, we expanded the stress and health knowledge base by identifying students' self-efficacy as an underlying mechanism under which to moderate the relationship between challenge stress and mental health. As a psychological attribute, self-efficacy is negatively related to psychological health [36]. Our study followed the previous research trail and supported the prior results. It extended further to include self-efficacy as a moderator to examine its role in the relationship between challenge stress and mental health. Third, this study, to some extent, supports the findings of the studies of Torres et al. [13] and Zhao et al. [16]. It was revealed in the former study that stress was negatively associated with their physical and emotional health among Latino students [13]. In the latter study, not only did self-efficacy predict the optimistic mindset but also moderated the effects of stress on coping strategy among Chinese undergraduate nursing students.

The current study has several practical implications. First, self-efficacy buffers the relationship between challenge stress and mental health. Students who believe they do not have the necessary capabilities to execute performance tend to experience more mental health issues. Therefore, college counselors and professors are alerted to pay special attention to low self-efficacy students. It is critically essential for colleges and universities to cultivate students' confidence in the study and to strengthen their learning abilities. Students may benefit when teachers give them moderately difficult assignments, capitalize on their interests, encourage them to explore, and give them frequent and focused feedback as all these practices relieve students' challenge stress. As mental health is also positively associated with challenge stress even for high self-efficacy students, these student populations are not immune to mental health problems and therefore they should not be ignored. In addition, challenge stress is positively related to mental health problems. Professors and college administrations need to alleviate students' academic stress to keep them mentally healthy. In addition to assigning appropriate projects and homework, it would also be wise to give individualized assignments based on students' interests, abilities, and stress levels.

\section{Limitations}

There are several limitations to this study. First, the participants were elicited through convenience and snowball sampling strategy from 7 universities, limiting the generalizability of the study results. Second, this study used a cross-sectional research design, therefore, causality cannot be derived from the results concerning the relationship among challenge stress, mental health, and self-efficacy. Future research would benefit if an experimental design or longitudinal study is adopted. Third, we only examined the impact of challenge stress on mental health among college students. Hindrance stress was not used as an exogenous variable in this study. Future researchers could use these two stressors simultaneously to investigate their different moderating effects on college students' mental health.

\section{Conclusion}

In this study, we examined the relationship between challenge stress self-efficacy and mental health among Chinese college students. Our findings indicated self-efficacy interacts with perceived challenge stress to affect the students' reported mental health. The current study emphasizes the importance of focusing on the low self-efficacy students as they are more likely to experience mental health problems.

Acknowledgement: The authors would like to express their appreciation to the administrators who approved this study at their universities. Also, we would like to thank all the students who participated in this study and/or distributed the online survey.

Funding Statement: This research received no financial support from any funding agency in the public, commercial, or not-for-profit sectors. 
Conflicts of Interest: The authors declare that there is no conflict of interest with respect to the research, authorship, and/or publication of this article.

\section{References}

1. Holland, D. (2016). College student stress and mental health: Examination of stigmatic views on mental health counseling. Michigan Sociological Review, 30, 16-43.

2. Cuijpers, P., Auerbach, R. P., Benjet, C. (2018). The world health organization world mental health international college student initiative: An overview. International Journal of Methods in Psychiatric Research, 28(2), e1761. DOI 10.1002/mpr.1761.

3. Cryer, B., McCraty, R., Childre, D. (2015). Pull the plug on stress. Harvard Business Review, 81, 102-107.

4. Borjalilu, S., Mohammadi, A., Mojtahedzadeh, R. (2015). Sources and severity of perceived stress among Iranian medical students. Iranian Red Crescent Medical Journal, 17(10), e17767. DOI 10.5812/ircmj.17767.

5. Zhang, L., Che, W., Li, B., Zhang, X. (2006). An epidemiological survey on the psychological stress status for students in 13 Chinese colleges. Chinese Journal of Epidemiology, 27(5), 387-391.

6. Li, Y., Lindsey, B. J., Yin, X., Chen, W. (2012). A comparison of American and Chinese students' perceived stress, coping styles, and health promotion practices. Journal of Student Affairs Research and Practice, 49(2), 211-227. DOI 10.1515/jsarp-2012-6298.

7. Zhang, K., Chu, Y. (2020). Chinese Students' Health Report.

8. Gritsenko, V., Skugarevsky, O., Konstantinov, V. (2020). COVID 19 fear, stress, anxiety, and substance use among Russian and Belarusian university students. International Journal of Mental Health and Addiction, 395(10227), 912. DOI 10.1007/s11469-020-00330-z.

9. Lee, J. S., Koeske, G. F., Sales, E. (2004). Social support buffering of acculturative stress: A study of mental health symptoms among Korean international students. International Journal of Intercultural Relations, 28(5), 399-414. DOI 10.1016/j.ijintrel.2004.08.005.

10. Ren, Q., Shen, Q., Benlan, Y., Liu, Y. (2018). Acculturative stress status of international medical students in China and the influencing on mental health. Chinese Journal of Practical Nursing, 34, 161-166.

11. Anastasiades, M. H., Kapoor, S., Wootten, J., Lamis, D. A. (2017). Perceived stress, depressive symptoms, and suicidal ideation in undergraduate women with varying levels of mindfulness. Archives of Women's Mental Health, 20(1), 129-138. DOI 10.1007/s00737-016-0686-5.

12. Liu, X., Ping, S., Gao, W. (2019). Changes in undergraduate students' psychological well-being as they experience university life. International Journal of Environmental Research and Public Health, 16(16), 2864. DOI 10.3390/ ijerph16162864.

13. Torres, J. B., Solberg, V. S. (2001). Role of self-efficacy, stress, social integration, and family support in Latino college student persistence and health. Journal of Vocational Behavior, 59(1), 53-63. DOI 10.1006/ jvbe.2000.1785.

14. Hobfoll, S. E. (1989). Conservation of resources: A new attempt at conceptualizing stress. American Psychologist, 44(3), 513-524. DOI 10.1037/0003-066X.44.3.513.

15. Qiu, S., Dooley, L. M., Xie, L. (2020). How servant leadership and self-efficacy interact to affect service quality in the hospitality industry: A polynomial regression with response surface analysis. Tourism Management, 78(4), 104051. DOI 10.1016/j.tourman.2019.104051.

16. Zhao, F. F., Lei, X. L., He, W. (2015). The study of perceived stress, coping strategy and self-efficacy of Chinese undergraduate nursing students in clinical practice. International Journal of Nursing Practice, 21(4), 401-409. DOI 10.1111/ijn.12273.

17. Chan, D. W. (2002). Stress, self-efficacy, social support, and psychological distress among prospective Chinese teachers in Hong Kong. Educational Psychology, 22(5), 557-569. DOI 10.1080/0144341022000023635.

18. LePine, J. A., LePine, M. A., Jackson, C. L. (2004). Challenge and hindrance stress: Relationships with exhaustion, motivation to learn, and learning performance. Journal of Applied Psychology, 89(5), 883-891. DOI 10.1037/0021-9010.89.5.883. 
19. Valentine, S. E., Shipherd, J. C. (2018). A systematic review of social stress and mental health among transgender and gender non-conforming people in the United States. Clinical Psychology Review, 66(7), 24-38. DOI 10.1016/j. cpr.2018.03.003.

20. Hubbard, K., Reohr, P., Tolcher, L., Downs, A. (2018). Stress, mental health symptoms, and help-seeking in college students. Psi Chi Journal of Psychological Research, 23(4), 293-305. DOI 10.24839/2325-7342.JN23.4.293.

21. Qiu, S., Alizadeh, A., Dooley, L. M., Zhang, R. (2019). The effects of authentic leadership on trust in leaders, organizational citizenship behavior, and service quality in the Chinese hospitality industry. Journal of Hospitality and Tourism Management, 40(1), 77-87. DOI 10.1016/j.jhtm.2019.06.004.

22. Podsakoff, P. M., MacKenzie, S. B., Podsakoff, N. P. (2012). Sources of method bias in social science research and recommendations on how to control it. Annual Review of Psychology, 63(1), 539-569. DOI 10.1146/annurevpsych-120710-100452.

23. Schwarzer, R., Jerusalem, M. (1995). Optimistic self-beliefs as a resource factor in coping with stress. Extreme stress and communities: Impact and intervention, pp. 159-177. Dordrecht: Springer.

24. Kessler, R. C., Green, J. G., Gruber, M. J. (2010). Screening for serious mental illness in the general population with the K6 screening scale: Results from the WHO World Mental Health (WMH) survey initiative. International Journal of Methods in Psychiatric Research, 19(S1), 4-22. DOI 10.1002/mpr.310.

25. Foster, K., Roche, M., Giandinoto, J. A., Furness, T. (2019). Workplace stressors, psychological well-being, resilience, and caring behaviours of mental health nurses: A descriptive correlational study. International Journal of Mental Health Nursing, 29(1), 56-68. DOI 10.1111/inm.12610.

26. Huang, N., Qiu, S., Alizadeh, A., Wu, H. (2020). How incivility and academic stress influence psychological health among college students: The moderating role of gratitude. International Journal of Environmental Research and Public Health, 17(9), 3237. DOI 10.3390/ijerph17093237.

27. Aiken, L. S., West, S. G., Reno, R. R. (1991). Multiple regression: Testing and interpreting interactions. UK: Sage.

28. Balaji, N. K., Murthy, P., Kumar, D. N., Chaudhury, S. (2019). Perceived stress, anxiety, and coping states in medical and engineering students during examinations. Industrial Psychiatry Journal, 28(1), 86-97. DOI 10.4103/ipj.ipj_70_18.

29. Pant, N., Srivastava, S. K. (2019). The impact of spiritual intelligence, gender and educational background on mental health among college students. Journal of Religion and Health, 58(1), 87-108. DOI 10.1007/s10943-017-0529-3.

30. Pedhazur, E. J., Kerlinger, F. N. (1982). Multiple regression in behavioral research. USA: Holt, Rinehart, and Winston.

31. Pandey, S., Elliott, W. (2010). Suppressor Variables in social work research: Ways to identify in multiple regression models. Journal of the Society for Social Work and Research, 1(1), 28-40. DOI 10.5243/jsswr.2010.2.

32. Brougham, R. R., Zail, C. M., Mendoza, C. M., Miller, J. R. (2009). Stress, sex differences, and coping strategies among college students. Current Psychology, 28(2), 85-97. DOI 10.1007/s12144-009-9047-0.

33. Wang, C. (2005). A research study regarding stress among college students. Chinese Journal of Health Psychology, 13, 311-313.

34. Eisenbarth, C. A. (2019). Coping with stress: Gender differences among college students. College Student Journal, $53,151-162$.

35. Negi, A. S., Khanna, A., Aggarwal, R. (2018). Psychological health, stressors and coping mechanism of engineering students. International Journal of Adolescence and Youth, 24(4), 511-520. DOI 10.1080/02673843.2019.1570856.

36. Thompson, M. N., Her, P., Fetter, A. K., Perez-Chavez, J. (2019). College student psychological distress: Relationship to self-esteem and career decision self-efficacy beliefs. Career Development Quarterly, 67(4), 282-297. DOI 10.1002/cdq.12199. 